\title{
Isolation of a conditional suppressor of leucine auxotrophy in Saccharomyces cerevisiae
}

\author{
Jack A. Heinemann, ${ }^{1}$ Robert G. Ankenbauer ${ }^{1}$ and Joe Horecka ${ }^{2}$ \\ Author for correspondence: Jack A. Heinemann. Tel: +1 4063639307 . Fax: +1 4063639204. \\ e-mail: jah@rml.niaid.pc.niaid.nih.gov
}

1 NIH, NIAID, LMSF, Rocky Mountain Laboratories, Hamilton, MT 59840, USA

2 Institute of Molecular Biology, Department of Biology, University of Oregon, Eugene, OR 97403, USA
Phenotypically and genotypically $($ leu2-3,112) Leu- cells of Saccharomyces cerevisiae gave rise to small colonies on medium devoid of leucine. This only occurred on plates with a high density of Leu cells or on medium supplemented with limiting quantities of leucine. Cells from these small colonies retained a growth advantage over their parent on limiting leucine supplements even after growth in a non-selecting (rich) medium. Therefore, the growth variants had acquired a heritable change. The phenotype was recessive and due to a change in a nuclear gene unlinked to the LEU2 locus. The phenotype provided a growth advantage only during leucine starvation; growth of the variants was indistinguishable from their parent on medium lacking the other essential supplements (histidine and uracil) required for the growth of the strain. $\left[{ }^{14} \mathrm{C}\right]$ Leucine uptake assays demonstrated that the variants were better able than their parents to accumulate leucine from their environments, and this ability extended to other hydrophobic amino acids. These results suggest that in the variants an amino acid uptake system has been derepressed rather than there having been reversion or extragenic suppression of the mutation in leucine biosynthesis. We designate the mutant gene responsible for the phenotype lup1 (for leucine uptake). The transport characteristics of the lup 1 mutants suggested that LUP1 is a regulatory component of an ammonium-regulated hydrophobic amino acid uptake system.

Keywords: Saccharomyces cerevisiae, leucine, auxotrophy, amino acid transport, adaptive mutagenesis

\section{INTRODUCTION}

The leu2-3,112 allele in the yeast Saccharomyces cerevisiae is a stable mutation. Because the allele does not revert, it has been used, for example, to demonstrate the delivery of large bacterial conjugative plasmids carrying the LEU2 gene during matings between bacteria and yeast (Heinemann \& Sprague, 1989). However, small colonies often do form during selection for $\mathrm{Leu}^{+}$cells on medium devoid of leucine, even in controls without bacterial donors. Nevertheless, cells from these small colonies remain leucine auxotrophs. We considered the possibility that growth was due to variants that have regained a limited ability to synthesize leucine (by reversion or extragenic suppression of leu2). Alternatively, phenotypic suppression of the $\mathrm{Leu}^{-}$phenotype could be due to variants that have acquired the ability to better concentrate leucine from their environment by alterations of leucine uptake pathways.
Growth of $\mathrm{Leu}^{-}$cells might be due to leucine 'scavengers', variants within the population that are Leu' but grow because they accumulate sufficient quantities of leucine by some other means, such as transporting leucine released by dying neighbours. Leucine is presumed to enter $S$. cerevisiae cells by at least three routes (Horak, 1986; Ramos et al., 1980; Wainer et al., 1988). The first, called the general amino acid permease (GAP1) system after the permease gene $G A P 1$, is a low-affinity, highvelocity pathway activated in response to nitrogen starvation (Grenson et al., 1970). Depending on the yeast strain and nitrogen source, the GAP1 system is inducible 5 to 460 -fold, and is thus classified as an adaptive system. The second pathway, also a low-affinity and high-velocity pathway, is specific for leucine and constitutive. The third pathway is a constitutive, leucine-specific, high-affinity and low-velocity system (Ramos et al., 1980). The BAP (branched amino acid permease) system also transports leucine in a high-affinity, low-velocity manner and may be 
identical to the high-affinity, low-velocity leucine transport system (Tullin et al., 1991). Because the GAP1 pathway is negatively regulated by ammonium, its contribution to leucine transport is negligible in low leucine/ high ammonium environments, and leucine must therefore enter by the other pathways under these conditions. There is some evidence to suggest that the constitutive leucine transport systems are also negatively regulated by ammonium salts (Kotliar et al., 1990).

In this report we present evidence that the small colonies formed by leu2-3,112 cells are not due to reversion or extragenic suppression of leu2. The mutation was recessive and did not map to the leu2 locus. Rather, variant cells were better abie to concentrate leucine in low leucine, high ammonium environments. The specificity of the variant phenotype for leucine and the rate of the uptake reaction indicated that derepression of the GAP1 pathway or increased activity of the low-affinity leucine uptake pathway were not the cause of the phenotype. However, the evidence is consistent with the inappropriate derepression of the high-affinity leucine uptake system. We have designated the mutant gene responsible for this phenotype, lup1, for leucine uptake.

\section{METHODS}

Relevant strain descriptions. Growth variants were derivatives of 329-6C (Mata his3-537: : TRP1:: his3-513 leu2-3,112 trp1 ura352 ade ). Strain 329-6C (Klein, 1988) was used as the parent, or wild-type, control in all experiments. Strain JY108 is a $\mathrm{Leu}^{+}$ derivative of 329-6C created by integration of the LEU2 gene into the 329-6C genome. LEU2 DNA was introduced by conjugation with bacteria as described previously (Heinemann \& Sprague, 1991). JY117 and JY118 were selected on solid medium from populations of $329-6 \mathrm{C}$ by growth in a leucinelimiting $\left(0.01 \mathrm{mg} \mathrm{ml}^{-1}\right)$ environment. JY126 is a spontaneous $\mathrm{His}^{+}$derivative of JY117. JY107 (Mata leu2-3,112 bis3 gal2 can1) was created by integration of the UR $A 3$ gene into the genome of SY1229 (Heinemann \& Sprague, 1989) following conjugation with bacteria as described (Heinemann \& Sprague, 1991). JY127 (MATa/a leu2-3,112/leu2-3,112 HIS3/bis3 URA3/ura3) was derived from a cross between JY126 and JY107. JY12714Aa (MATa lup1 leu2-3,112 ura3 bis3) was isolated as a haploid segregant of JY127 and mated to SY2512 (MATa LEU2 ura3 arg4 ade1) to determine allelic identity between $l u p 1$ and LEU2.

Media and nomenclature. Standard media preparations and genetic terminology are as described by Sherman (1991), except that the leucine concentration in synthetic medium was normally $0.08 \mathrm{mg} \mathrm{ml}^{-1}$. SC medium contained adenine, arginine, tryptophan, methionine, uracil (all $0.02 \mathrm{mg} \mathrm{ml}^{-1}$ ); $0.06 \mathrm{mg}$ lysine $\mathrm{ml}^{-1} ; 0.03 \mathrm{mg}$ tyrosine $\mathrm{ml}^{-1} ; 0.05 \mathrm{mg}$ phenylalanine $\mathrm{ml}^{-1}$; $0.2 \mathrm{mg}$ threonine $\mathrm{ml}^{-1} ; 0.08 \mathrm{mg}$ leucine $\mathrm{ml}^{-1}$ (Heinemann \& Sprague, 1991). Several types of omission media were used. SCleu, SC-ura, SC-his and SC-trp are synthetic complete medium lacking only leucine, uracil, histidine or tryptophan, respectively. MA medium was the equivalent of SD (Sherman, 1991). $\mathrm{MP}$ medium was similar to MA with $0.1 \%$ proline and $1 \times$ yeast nitrogen base without amino acids or $\left(\mathrm{NH}_{4}\right)_{2} \mathrm{SO}_{4}$ (Difco) substituting for $1 \times$ yeast nitrogen base without amino acids (Difco). MA and MP media were supplemented with leucine, histidine, uracil and adenine (ade) as appropriate at the concentrations listed above.
Culturing procedures. Yeast stocks were maintained at $-70{ }^{\circ} \mathrm{C}$ in $15 \%(\mathrm{v} / \mathrm{v})$ glycerol and streaked fresh onto solid YPD medium. Growth medium $(10 \mathrm{ml})$ was inoculated with a single colony and grown to saturation. These cultures were either used directly or diluted into flasks so their growth could be monitored in a Klett-Summerson colorimeter. Before plating on SC-leu, saturated cultures were diluted into MA medium and incubated at $30^{\circ} \mathrm{C}$ until their growth ceased. Markers were routinely tested by replica plating (Sherman, 1991).

Phenotype frequencies. Frequencies at which phenotypes were isolated from a population of cells was determined by dividing the titre of variants by the titre of cells in the input culture. Input titres were determined by applying dilutions to YPD medium.

Radio-labelled amino acid uptake assays. $S$. cerevisiae cultures were grown in $\mathrm{MA}+$ leu + his + ura + ade or $\mathrm{MP}+$ leu + his + ura + ade medium at $30^{\circ} \mathrm{C}$ until the culture reached saturation. Cells were pelleted from $5 \mathrm{ml}$ cultures by centrifugation, washed once with water and resuspended in $50 \mathrm{ml} \mathrm{MA}+$ his + ura + ade or $\mathrm{MP}+$ his + ura + ade. Cultures were incubated in $\mathrm{MA}+$ his + ura +ade or $\mathrm{MP}+$ his + ura + ade for $5 \mathrm{~h}$ at $30^{\circ} \mathrm{C}$ to deplete the intracellular leucine and enter the cells into leucine starvation. At $5 \mathrm{~h}$, dilutions of the cultures were plated on YPD plates to determine the c.f.u. $\mathrm{ml}^{-1}$. Concentration-dependent uptake assays were initiated by adding varying amounts of radiolabelled amino acids to $200 \mu \mathrm{l}$ aliquots of the different $S$. cerevisiae cultures and incubating at $30^{\circ} \mathrm{C}$ with shaking. The amount of radiolabelled amino acids added yielded concentrations ranging from $0 \cdot 3125-10 \mu \mathrm{M}$ as indicated in the text and figure legends. Samples were removed after $15 \mathrm{~min}$ and filtered through $0.45 \mu \mathrm{m}$ cellulose acetate filters (cat. no. OE67, Schleicher \& Schuell) in a vacuum-drawn filter manifold (1225 sampling manifold, Millipore). Filters were hydrolysed in $2 \mathrm{M} \mathrm{HCl}$ at $100^{\circ} \mathrm{C}$ for $1.5 \mathrm{~h}$, scintillation cocktail was added to the hydrolysate, and the d.p.m. of the sample determined on a Beckman LS 6000LL scintillation spectrometer using the single label d.p.m. program with a ${ }^{14} \mathrm{C}$ or ${ }^{35} \mathrm{~S}$ quench curve calibration.

To assay for GAP1 activity, cells were grown in MA+leu+ his + ura + ade at $30^{\circ} \mathrm{C}$ until the culture reached saturation. The cells were washed once with water, diluted into $20 \mathrm{ml}$ MA+ leu + his + ura +ade or MP+leu+his + ura + ade, and incubated at $30^{\circ} \mathrm{C}$ for $4 \mathrm{~h}$. At $4 \mathrm{~h}$, the cells were washed once with water to remove amino acids and placed into an identical volume of either MA + ade + ura or MP + ade + ura. The amino acids were removed, since their presence would interfere with subsequent analysis of GAP1 activity. Cells were incubated for an additional hour at $30^{\circ} \mathrm{C}$ and then transport assays were done as described above, except that $\mathrm{L}-\left[{ }^{14} \mathrm{C}\right]$ citrulline was used at a single concentration of $100 \mu \mathrm{M}$. All radiolabelled amino acids were obtained from New England Nuclear and were used at the following specific activities: L- [U- $\left.{ }^{14} \mathrm{C}\right]$ leucine, specific activity, $157 \cdot 15 \mathrm{mCi} \mathrm{mmol}^{-1} ; \mathrm{L}_{-}^{-}\left[\mathrm{U}_{-}{ }^{14} \mathrm{C}\right] \mathrm{phenylalanine,} 100 \mathrm{mCi} \mathrm{mmol}^{-1}$; $\mathrm{L}-\left[{ }^{35} \mathrm{~S}\right]$ methionine, $400 \mathrm{mCi} \mathrm{mmol}^{-1} ; \quad \mathrm{L}-\left[{ }^{14} \mathrm{C}\right.$-ureido $]$ citrulline, $22 \cdot 5 \mathrm{mCi} \mathrm{mmol}^{-1}(1 \mathrm{Ci}=37 \mathrm{GBq})$.

\section{RESULTS}

The leu2-3,112 allele of the yeast $S$. cerevisiae was created by in vivo recombination between the two different frameshift mutations leu2-3 and leu2-112 (Hinnen et al., 1978; Klein $\&$ Petes, 1981). A leu2-3,112 genotype is recessive and it renders haploid and homozygous diploid strains completely dependent upon the addition of leucine to minimal growth medium. Strains with the double mutant allele revert to leucine prototrophy $\left(\mathrm{Leu}^{+}\right)$so infrequently that 


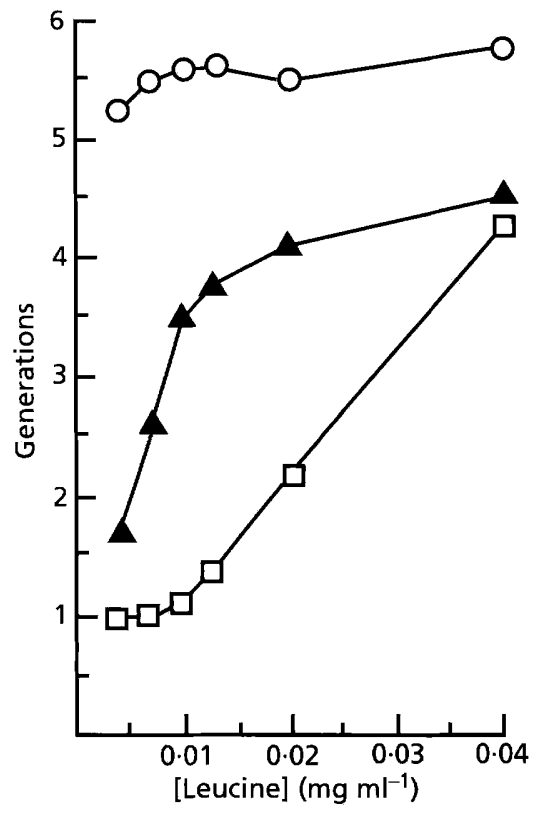

Fig. 1. Growth in leucine-deprived environments. The progenitor leu2-3,112 strain 329-6C ( $\square$ ), its $\mathrm{Leu}^{+}$derivative, JY108 (O) and a representative Leu $^{-}$variant, JY117 (A) were prepared as described in Methods, titred, and diluted into liquid SC-leu medium supplemented with various amounts of leucine. After $23 \mathrm{~h}$ incubation, titres were again determined and the number of generations calculated.

the allele is considered a functional equivalent of a deletion (Hinnen et al., 1978). We have never observed a spontaneous leucine prototroph arising from strains harbouring the leu2-3,112 allele [fewer than 1 in $\sim 10^{10}$ cells screened (Heinemann \& Sprague, 1989, and unpublished observations)]. Prolonged incubation under selection was also ineffective at raising prototrophs (fewer than 1 in $\sim 10^{9}$ cells screened for approximately 3 weeks).

Leucine auxotrophs, however, formed colonies on medium lacking leucine. Their colonies remained small and they did not form colonies when transferred to fresh SCleu plates. Appearance of these colonies was dependent on a heavy inoculum of yeast cells.

Small colonies were not contaminants. The parental strain, 329-6C, has a number of other auxotrophic markers. 329-6C is Ura- (ura3-52), $\mathrm{Ade}^{-}$(ade6), $\mathrm{His}^{-}$(bis3537 and his3-513; see Methods), and unstably Trp ${ }^{+}$[TRP1 is integrated between duplicated his 3 alleles and is lost at a frequency of $\sim 1 \times 10^{-6}$ by intrachromosomal recombination (Klein, 1988)]. The genotypes of small colonies were routinely confirmed for these auxotrophies, as was their ability to grow on YPD (rich) medium.

Several lines of evidence, discussed below, implied that the cells which gave rise to small colonies represented an altered amino acid uptake phenotype. As such, the variants were designated $\mathrm{Lup}^{+}$, for leucine uptake. Lup ${ }^{+}$ colonies were characteristically found on plates inoculated with approximately $10^{7}$ to $10^{8}\left(\mathrm{Leu}^{-}\right)$cells. This suggested that colony-formers possessed enhanced capacity to grow in a leucine-limiting, but not deprived, environment. When large numbers of cells are plated, the leucine released from dead cells might be utilized by 'scavengers'. Consistent with the variants having an enhanced capacity to acquire leucine from the environment, they grew in both liquid and solid medium supplemented with $0.01 \mathrm{mg}$ leucine $\mathrm{ml}^{-1}$, a concentration that did not support the growth of their progenitor (Fig. 1).

\section{Genetic characterization of the Lup ${ }^{+}$phenotype}

These variants were genetically stable but were not Leu ${ }^{+}$ because they could not grow on SC-leu. Six independently selected variants were purified for further examination. They were either restreaked on low leucine medium $\left(0.01 \mathrm{mg}\right.$ leucine $\left.\mathrm{ml}^{-1}\right)$ and then passaged on rich medium or were streaked directly to YPD. Following sequential passage through solid and liquid YPD medium, variants retained the ability to grow on medium with low concentrations of leucine (Fig. 1). Their growth characteristic was therefore heritable. However, unlike LEU2containing derivatives of the progenitor (such as JY108), growth of these variants was restricted to medium with at least $0 \cdot 01 \mathrm{mg}$ leucine $\mathrm{ml}^{-1}$ (Fig. 1).

Variants were selected directly from populations of 329-6C by plating liquid YPD cultures onto solid medium supplemented with $0.01 \mathrm{mg}$ leucine $\mathrm{ml}^{-1}$. Tenfold dilutions of cultures beginning with approximately $10^{7}$ cells $\mathrm{ml}^{-1}$ were applied to the selective medium. Colonies appeared in 2-4 d at a frequency of $4 \times 10^{-6} \pm 1 \times 10^{-6}$. Based on the number of cells initially applied to plates, by day 12 of incubation the variant phenotype arose at a frequency as high as $3 \times 10^{-2}$.

The growth phenotype was recessive. Five independent diploids (e.g. JY127) derived from matings between a Lup $^{+}$(JY126) and an unrelated Lup leu2 (JY107) strain were tested for their ability to grow on $0.01 \mathrm{mg}$ leucine $\mathrm{ml}^{-1}$. Diploids formed by mating JY126 and SY1229 were selected on MA + Leu medium (Table 1). In contrast to the $\mathrm{Lup}^{+}$parent, none of the diploids grew on SC-Leu medium ('Table 1). Therefore, the variant phenotype was not the result of partial reversion of the leucine biosyn-

Table 1. Recessive/dominant test of lup1

Results are representative of five independent heterozygotes.

\begin{tabular}{|c|c|c|}
\hline \multirow[t]{2}{*}{ Strain } & \multicolumn{2}{|c|}{ Growth } \\
\hline & $\mathbf{M A}+\mathbf{L e u}$ & $\begin{array}{c}\text { SC-Leu }+ \\
0.01 \mathrm{mg} \\
\text { leucine } \mathrm{ml}^{-1}\end{array}$ \\
\hline JY126 & - & + \\
\hline SY1229 & - & - \\
\hline JY126 × SY1229 & + & - \\
\hline
\end{tabular}


Table 2. Tetrad analysis

\begin{tabular}{|ccccc|}
\hline $\begin{array}{c}\text { Linkage } \\
\text { test }\end{array}$ & $\begin{array}{c}\text { Parental } \\
\text { ditypes }\end{array}$ & $\begin{array}{c}\text { Non- } \\
\text { parental } \\
\text { ditypes }\end{array}$ & Tetratypes \\
\hline A & $\operatorname{lup} 1-M A T$ & 10 & 5 & 37 \\
B & $\operatorname{lup1-leu2}$ & 1 & 3 & 7 \\
\hline
\end{tabular}

thesis mutation because this class of mutants would be expected to be dominant.

The mutant phenotype segregated as a single nuclear gene. Fifty-two tetrads were dissected following sporulation of the JY126 $\times$ JY107 diploid. The mutant phenotype segregated $2: 2$ in all 52 tetrads. The mutation identified a single nuclear gene, which in the wild-type we designated LUP1.

lup1 was not allelic to LEU2. The LEU2 locus is linked to $M A T$ on chromosome III. As can be seen in Table 2 (line A), the ratio of parental ditype to non-parental ditype to tetratype tetrads with respect to $M A T$ and $\operatorname{lu} p 1$ was approximately $1: 1: 4$, showing that lup1 is not linked to $M A T$ (Sherman \& Wakem, 1991). Moreover, LUP1 was not linked to the LEU2 locus. A MATa lup1 leu2-3,112 segregant (JY12714Aa) from above (JY127) was mated to a $M A T \alpha L E U 2$ strain (SY2512), induced to sporulate, and 11 tetrads were dissected (Table 2, line B). From the ratio of the tetrad types we concluded that LEU2 and $\operatorname{lup} 1$ sorted independently. Finally, we isolated several leu2 LUP1 haploids following sporulation of the above diploid. The leu2 LUP1 haploids could only be recovered if $L E U 2$ and $\operatorname{lup} 1$ were separate genes (i.e. the diploid genotype was LEU2/leu2 LUP1/lup1). Therefore, LEU2 and lup1 cannot be alleles of the same gene.

\section{Physical characterization of the Lup ${ }^{+}$phenotype}

Gradient assays. Lup $^{+}$cells were examined for evidence of a general change in their ability to grow on limiting concentrations of other essential nutrients (histidine and uracil for strain 329-6C) as opposed to a change specific for leucine starvation. Several nutrient gradients were created on omission media, and the growth of Lup ${ }^{+}$ (lup1), the Lup ${ }^{-}$progenitor (329-6C) and an isogenic I_UP1 LEU2 strain (JY108) was measured. SC-ura, SChis or SC-leu plates were supplemented with $0.06 \mathrm{mg}$ uracil, $0.06 \mathrm{mg}$ histidine or $0.2 \mathrm{mg}$ leucine, respectively, as a droplet in the centre of the plate (final concentration approximately $0 \cdot 1 \times$ standard for the entire plate). After the droplet dried, 100 to 1000 -fold dilutions of saturated cultures of Lup $^{+}$, Lup ${ }^{-}$or LEU2 strains were applied to the surface of the plate in a spoke-like fashion with the arms of the spoke extending outward from the centre. The extent to which growth extended from the plate centre after $18 \mathrm{~h}$ of incubation was measured. Lup ${ }^{+}$ cultures were indistinguishable from either the Lup ${ }^{-}$or LEU2 strain on uracil or histidine gradients (all grew

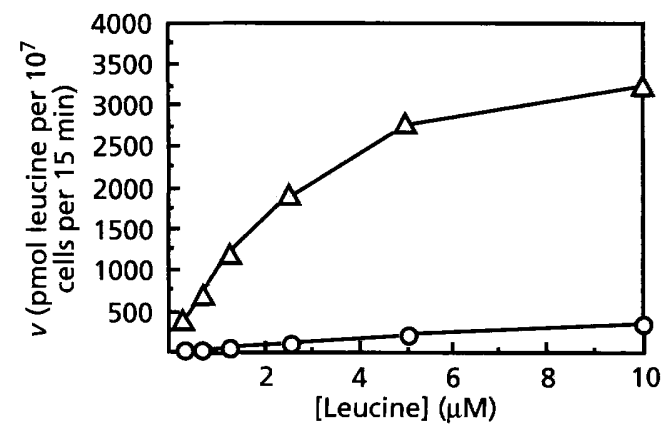

Fig. 2. Uptake of $\left[{ }^{14} \mathrm{C}\right]$ leucine by $\mathrm{S}$. cerevisiae strain $329-6 \mathrm{C}(\mathrm{O})$

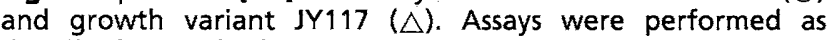
described in Methods.

equal distances from the plate centre. In stark contrast, when assayed on a leucine gradient, the Lup ${ }^{+}$cells grew twice as far along the gradient $(2 \cdot 8 \pm 0 \cdot 2 \mathrm{~cm})$ as did Lup $(1.6 \pm 0.06 \mathrm{~cm})$.

Leucine uptake and inhibition of leucine uptake. The ability of the Lup ${ }^{+}$isolate JY117 to take up $\left[{ }^{14} \mathrm{C}\right]$ leucine was compared to that of the progenitor 329-6C. At concentrations of $\left[{ }^{14} \mathrm{C}\right]$ leucine ranging from 0.3125 to $10 \mu \mathrm{M}$, leucine-starved JY117 transported 10-20 times as much leucine as did the leucine-starved progenitor strain (Fig. 2). Similar results were obtained with another independently isolated $\mathrm{Lup}^{+}$variant, JY118. A Lineweaver-Burk plot of leucine uptake kinetics of Lup ${ }^{+}$ cells showed a $V_{\max }$ of 4570 pmol leucine per $10^{7}$ cells per $15 \mathrm{~min}$ and $\mathrm{a} K_{\mathrm{m}}$ of $3.7 \mu \mathrm{M}\left(r^{2}=1 \cdot 0\right)$, indicating that the uptake system was saturable.

In similar assays, the specificity of $\left[{ }^{14} \mathrm{C}\right]$ leucine uptake was also analysed (Table 3 ). The Lup ${ }^{+}$variant, JY117, and the progenitor strain, 329-6C, were incubated in the presence of $10 \mu \mathrm{M}\left[{ }^{14} \mathrm{C}\right]$ leucine with or without $1 \mathrm{mM}$ unlabelled competitor: leucine, methionine, isoleucine, phenylalanine, valine, histidine, lysine, tryptophan, threonine and serine, respectively. Leucine uptake was strongly inhibited by a 100 -fold higher concentration of the various hydrophobic amino acids but not at all by histidine, lysine, threonine and serine when cells were grown in the presence of ammonium. A 100 -fold higher concentration of unlabelled leucine caused $>95 \%$ inhibition of $\left[{ }^{14} \mathrm{C}\right]$ leucine transport in all cases. Remarkably, phenylalanine was the next most effective competitor of leucine transport. This was unexpected because the alkyl side chains of isoleucine, valine and methionine more resemble leucine than the phenyl group of phenylalanine.

Uptake of other hydrophobic amino acids. The inhibition of $\left[{ }^{14} \mathrm{C}\right]$ leucine transport by various hydrophobic amino acids suggested that the $\mathrm{Lup}^{+}$transport phenotype was not limited to the transport of leucine. Since phenylalanine and methionine were strong inhibitors of leucine transport, uptake of these amino acids by Lup $^{+}$and Lup $^{-}$cells was assayed. Like leucine, the transport of both phenylalanine (Fig. 3a) and methionine 

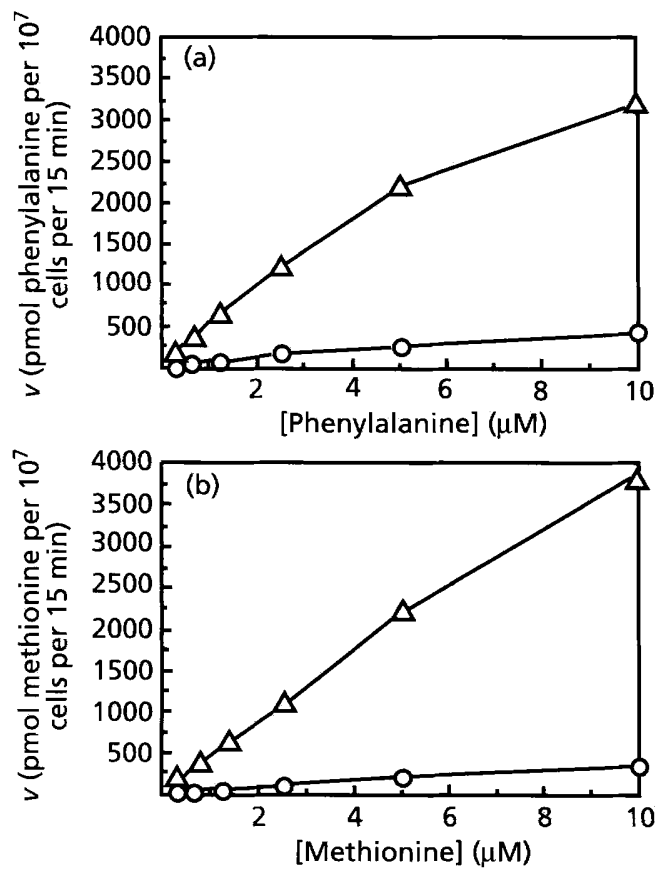

Fig. 3. Uptake of $\left[{ }^{14} \mathrm{C}\right]$ phenylalanine (a) and $\left[{ }^{35} \mathrm{~S}\right]$ methionine (b) by S. cerevisiae strain 329-6C $(O)$ and growth variant JY117 $(\triangle)$. Assays were performed as described in Methods.

(Fig. 3b) into the Lup ${ }^{+}$strain JY117 was strongly elevated relative to $329-6 \mathrm{C}$. These results correlate well with the inhibition assays (Table 3) and suggest that $\mathrm{Lup}^{+}$cells have an enhanced ability to transport hydrophobic amino acids. All hydrophobic amino acids are likely to be substrates for the system identified by the lup 1 allele (the 'LUP1' system) in view of the rapid uptake of three structurally distinct amino acids studied here-leucine, phenylalanine and methionine. Indeed, the phenotype exhibited by a $\operatorname{lup} 1$ trp 1 strain on SC-trp medium (data not shown) was similar to the Lup ${ }^{+}$phenotype exhibited by a lup1 leu2 strain on SC-leu.

Ammonium regulation. When grown in the presence of ammonium, the Lup ${ }^{+}$strain JY117 transported leucine six times faster than did 329-6C (Table 3). However, 329$6 \mathrm{C}$ grown in MP medium, where proline is the sole nitrogen source, transported leucine at rates similar to JY117 (Table 3). Growth in MP medium derepresses the GAP1 system, thereby increasing the transport of all amino acids. Thus, we considered the possibility that GAP1 was inappropriately derepressed in the presence of ammonium in lupl strains.

Increased leucine transport into JY117 and MP-grown 329-6C, however, was not due to derepression of GAP1. The GAP1 system has a much higher affinity for basic amino acids than acidic, neutral or hydrophobic amino acids (Grenson et al., 1970). Woodward \& Cirillo (1977) have shown that a 10 -fold higher concentration of unlabelled histidine or lysine inhibited $>95 \%$ of the transport of the hydrophobic amino acid valine via the GAP1 system. In the inhibition assays reported here, a
Table 3. Inhibition of leucine transport by competing amino acids

Results ate representative of three experimental determinations. Cells were grown in MA (minimal with ammonium sulfate as nitrogen source) or MP (minimal with proline as nitrogen source). Potential inhibitors were added to assay mixtures at a concentration of $1 \mathrm{mM}, 100$ times the concentration of $\left[{ }^{14} \mathrm{C}\right]$ leucine. The concentration of $\left[{ }^{14} \mathrm{C}\right]$ leucine $\left(157 \cdot 15 \mathrm{mCi} \mathrm{mmol}^{-1}\right)$ in the assays was $10 \mu \mathrm{M}$.

\begin{tabular}{|c|c|c|c|}
\hline $\begin{array}{l}\text { Strain/ } \\
\text { growth } \\
\text { medium }\end{array}$ & $\begin{array}{l}\text { Amino } \\
\text { acid }\end{array}$ & $\begin{array}{c}D \\
\text { (pmol leucine } \\
\text { per } 10^{7} \text { cells } \\
\text { per } 15 \mathrm{~min} \text { ) }\end{array}$ & $\begin{array}{l}\text { Percentage } \\
\text { inhibition }\end{array}$ \\
\hline \multirow[t]{11}{*}{$329-6 \mathrm{C} / \mathrm{MA}$} & None & $442 \cdot 0$ & 0 \\
\hline & Leucine & 13.5 & 97 \\
\hline & Methionine & $50 \cdot 5$ & 89 \\
\hline & Isoleucine & $27 \cdot 5$ & 94 \\
\hline & Phenylalanine & $17 \cdot 5$ & 96 \\
\hline & Valine & $76 \cdot 0$ & 83 \\
\hline & Histidine & $440 \cdot 5$ & 0 \\
\hline & Lysine & $461 \cdot 5$ & 0 \\
\hline & Tryptophan & $213 \cdot 0$ & 52 \\
\hline & Threonine & $349 \cdot 0$ & 21 \\
\hline & Serine & $458 \cdot 5$ & 0 \\
\hline \multirow[t]{11}{*}{ JY117/MA } & None & $2732 \cdot 5$ & 0 \\
\hline & Leucine & $104 \cdot 0$ & 96 \\
\hline & Methionine & $591 \cdot 5$ & 78 \\
\hline & Isoleucine & $365 \cdot 5$ & 87 \\
\hline & Phenylalanine & $194 \cdot 0$ & 93 \\
\hline & Valine & $993 \cdot 5$ & 64 \\
\hline & Histidine & $3316 \cdot 5$ & 0 \\
\hline & Lysine & $3520 \cdot 5$ & 0 \\
\hline & Tryptophan & $1897 \cdot 0$ & 31 \\
\hline & Threonine & $2934 \cdot 5$ & 0 \\
\hline & Serine & $3215 \cdot 0$ & 0 \\
\hline \multirow[t]{11}{*}{$329-6 \mathrm{C} / \mathrm{MP}$} & None & $2048 \cdot 5$ & 0 \\
\hline & Leucine & $71 \cdot 5$ & 97 \\
\hline & Methionine & $409 \cdot 0$ & 80 \\
\hline & Isoleucine & $218 \cdot 0$ & 89 \\
\hline & Phenylalanine & $189 \cdot 0$ & 91 \\
\hline & Valine & $580 \cdot 0$ & 72 \\
\hline & Histidine & $1727 \cdot 0$ & 16 \\
\hline & Lysine & $1964 \cdot 0$ & 4 \\
\hline & Tryptophan & $1297 \cdot 5$ & 37 \\
\hline & Threonine & $1704 \cdot 5$ & 17 \\
\hline & Serine & $1725 \cdot 5$ & 16 \\
\hline
\end{tabular}

100 -fold higher concentration of histidine or lysine had no effect on leucine transport in JY117 or 329-6C grown in MA medium (Table 3). Further evidence that the GAP1 and LUP1 systems are distinct derived from studies of $\mathrm{L}^{-}$ $\left[{ }^{14} \mathrm{C}\right]$ citrulline transport. L-Citrulline transport is mediated only by GAP1 (Grenson et al., 1970). As can be seen when Lup $^{+}$and Lup cells were grown in GAP1-repressing (MA) and GAP1-derepressing (MP) medium, L$\left[{ }^{14} \mathrm{C}\right]$ citrulline uptake remained regulated by ammonium 
Table 4. Induction of GAP1 system in LUP1 and lup1 strains

Results are representative of three experimental determinations. The concentration of $\mathrm{L}-\left[{ }^{14} \mathrm{C}\right]$ citrulline $\left(22.5 \mathrm{mCi} \mathrm{mmol}^{-1}\right)$ in the assays was $100 \mu \mathrm{M}$ and uptake values are expressed as velocity (pmol L- $\left[{ }^{14} \mathrm{C}\right]$ citrulline per $10^{7}$ cells per $15 \mathrm{~min}$ ). Cells were grown overnight in $\mathrm{MA}+$ his + leu + ura + ade (minimal with ammonium sulfate as nitrogen source), washed with water and then diluted into either MA + his + leu + ura + ade or $\mathrm{MP}+\mathrm{his}+\mathrm{leu}+\mathrm{ura}+$ ade (minimal with proline as nitrogen source) and incubated at $30^{\circ} \mathrm{C}$ for $4 \mathrm{~h}$. At $4 \mathrm{~h}$, the cells were washed once with water to remove amino acids from the medium and placed into an identical volume of either $\mathrm{MA}+$ ura + ade or MP + ura + ade and incubated for an additional hour prior to initiating citrulline uptake assays. Induction (-fold) is the ratio of citrulline transport by prolinegrown cells over citrulline transport by ammonium sulfategrown cells.

\begin{tabular}{|lrr|}
\hline Nitrogen source & \multicolumn{2}{c|}{ L-[ ${ }^{14}$ C $]$ citrulline uptake } \\
\cline { 2 - 3 } & 329-6C & JY117 \\
\hline & & 325 \\
Ammonium sulfate & 254 & 17502 \\
Proline & 5266 & 54 \\
Induction (-fold) & 21 & \\
\hline
\end{tabular}

in both wild-type and Lup ${ }^{+}$cells (Table 4). Therefore, GAP1 is not responsible for the transport of leucine into Lup $^{+}$cells (or Lup ${ }^{-}$cells grown in MA medium) and LUP1 must be a regulatory component of a separate amino acid transport system.

Leucine transport into 329-6C $\left(\mathrm{Lup}^{-}\right)$cells grown in MP medium was to some extent inhibited by all amino acids. Following induction of GAP1, lysine, histidine, serine and threonine inhibited leucine transport into 329-6C from 4 to $17 \%$. Therefore, the GAP1 system accounted for a maximum of $5-15 \%$ of the leucine transport observed in 329-6C grown in GAP1-derepressing conditions. The majority of leucine transport into these cells must occur by another pathway which is ammoniumrepressible. Based on the similarities of leucine transport rates and the inhibition profiles (Table 3) of JY117 and MP-grown 329-6C, we conclude that LUP1 is a regulatory component of an ammonium-repressible hydrophobic amino acid transport system in $S$. cerevisiae, distinct from GAP1. In lup1 strains, the hydrophobic amino acid transport system has been liberated from ammonium repression. Consistent with the $\mathrm{Lup}^{+}$phenotype being recessive, we suggest that LUP1 is a repressor of the hydrophobic amino acid uptake pathway.

\section{DISCUSSION}

Lup $^{+}$colonies of $\mathrm{Leu}^{-}$yeast form on minimal medium in the absence of leucine. Reconstruction experiments using plates supplemented with extra leucine $\left(0.01 \mathrm{mg} \mathrm{ml}^{-1}\right)$ showed that growth of $\mathrm{Leu}^{-}$cells on SC-leu medium could not have been due to trace amounts of leucine contaminating the medium. On SC-leu medium supplemented with $0.01 \mathrm{mg}$ leucine $\mathrm{ml}^{-1}$, variants arose at a frequency of $4 \times 10^{-6}$. If growth were due to leucine in unsupplemented medium, lawns would have been expected on plates with $0.01 \mathrm{mg}$ leucine $\mathrm{ml}^{-1}$ and colonies would have been expected on SC-leu plates with fewer than $10^{7}$ input cells.

The variants had acquired a stable change. Unlike a LEU2 strain, variants could not be cultured in the absence of leucine. They were therefore not true revertants. Because the trait was recessive (Table 1), it was unlikely to be a partial revertant of leu2 (Horak, 1986).

The stability of the change, as evidenced by the variants' ability to grow on limiting concentrations of leucine after culture under non-selective conditions, suggested that it was genetic. That the trait was a gene mutation, as opposed to an epigenetic change (Novick \& Weiner, 1957; Pillus \& Rine, 1989), was confirmed when it segregated $2: 2$ among the meiotic offspring of a heterozygous diploid.

Mapping experiments further confirmed that the Lup ${ }^{+}$ phenotype was not a result of partial reversion of the leu23,112 allele. $\operatorname{lu} p 1$ was not linked to either $M A T$ (which is linked to LEU2) or LEU2 (Table 2). Furthermore, LUP1 leu2 spores were readily isolated from a diploid whose parents were either $L E U 2$ or $\operatorname{lup} 1$, respectively. If lup1 had been allelic to LEU2 (i.e. the diploid genotype had been $L E U 2 / l u p 1$ vs LEU2/leu2 LUP1/lup1), only LEU2 or lup1 haploids would be recovered following sporulation.

The phenotypic change was confined to the uptake of leucine and other hydrophobic amino acids. Gradient assays were used to show that growth was enhanced only on medium limited for leucine and not on medium limited for other required supplements for strain $329-6 \mathrm{C}$, in this case histidine and uracil.

Uptake assays using radiolabelled leucine demonstrated that Lup $^{+}$cells were significantly better at accumulating extracellular leucine than wild-type cells (Figs 1 and 2). This enhanced ability to concentrate leucine provided Lup $^{+}$cells with a growth advantage over wild-type cells in leucine-poor environments ranging from at least 0.005 to $0.04 \mathrm{mg}$ leucine $\mathrm{ml}^{-1}$ (Fig. 1). This permitted variants to form detectable colonies on leucine-deprived (at cell concentrations of $\geqslant 10^{7}$ cells per plate) and leucinelimiting $\left(0.01 \mathrm{mg} \mathrm{ml}^{-1}\right)$ medium.

Competition experiments using various unlabelled amino acids demonstrated the transport specificity for hydrophobic amino acids. Moreover, these experiments indicated that the Lup ${ }^{+}$character is not due to derepression of the GAP1 pathway in the presence of ammonium. Firstly, the GAP1 pathway strongly prefers the basic amino acids lysine and histidine to leucine (Woodward \& Cirillo, 1977) and the competition assays indicated that neither of these was an effective competitor of leucine transport in lup1 cells. Secondly, the Lup ${ }^{+}$cells were not advantaged on histidine gradients. Thirdly, the amino acid citrulline, which is transported only by the GAP1 pathway, was still 
regulated by ammonium in the $\operatorname{lup} 1$ strain JY117 and the absolute amount of citrulline uptake was similar in the LUP 1 and $l u p 1$ strains in the presence of ammonium.

The absolute rate and specificity of the transport phenotype displayed in $\mathrm{Lup}^{+}$(compared to MP-grown 329-6C) cells, and the fact that the trait was recessive, suggested the inactivation of a repressor of the high-affinity leucine uptake system, but not of the GAP1 or the low-affinity leucine uptake system. The high transport velocities observed with the Lup ${ }^{+}$phenotype at low concentrations of substrate $(\leqslant 10 \mu \mathrm{M})$ indicate that this is a high-affinity system (Ramos et al., 1980; Wainer et al., 1988). The virtually identical leucine transport inhibition profiles of 329-6C (Lup ${ }^{-}$) and JY117 (Lup ${ }^{+}$) suggest that the same transport system is present in both strains and that this transport system is derepressed in JY117. We therefore propose that LUP1 mediates ammonium repression of the high-affinity/low-velocity leucine uptake pathway.

There is significant phenotypic correlation between Lup ${ }^{+}$ cells and aat1 mutants of S. cerevisiae (Garrett, 1989). Growth of leu2 at1 strains is inhibited by isoleucine, phenylalanine, methionine, valine and tyrosine (Garrett, 1989), a group of amino acids similar to the inhibitors of leucine transport reported here. Garrett (1989) suggested that $A A T 1$ is required for leucine transport in the presence of hydrophobic amino acids. Under such conditions, aat 1 leu 2 cells are deprived of leucine because the other hydrophobic amino acids block leucine transport. We propose the following model to fit these observations. $A A T 1$ is required for function of the low-affinity/highvelocity leucine uptake system. In aat 1 leu 2 cells, the only mechanism remaining for the uptake of leucine is the high-affinity, low-velocity pathway, which is probably controlled by LUP1. Since the hydrophobic amino acids are effective competitors of leucine for uptake by the LUP1 pathway, they inhibit the transport of leucine and thereby the growth of aat1 leu 2 cells.

The inhibition profiles observed in this study do not correspond with the results obtained from studies on the BAP (branched-chain amino acid permease) system (Tullin et al., 1991). In contrast to our results, leucine transport by the BAP system is not inhibited by phenylalanine or methionine, but was somewhat inhibited by histidine and lysine. We did not observe the transport phenotype of the BAP system in our strains, which may simply be a reflection of the different genetic backgrounds. The presence of similar high-affinity leucine/hydrophobic amino acid transport systems in both Lup L $^{-}$(329-6C) and aat1 (Garrett, 1989) cells suggests that the LUP1 system is identical to the high-affinity leucine transport system reported by Ramos et al. (1980).

Determining the nature of the change (e.g. transposon insertion or point mutation) awaits isolation of $\operatorname{lup} 1$. The Lup $^{+}$phenotype was eventually displayed by a large percentage of the population ( $\sim 1$ per 100 input cells in $12 \mathrm{~d}$ ). Even the initial frequency of $\sim 1$ variant per $10^{6}$ input cells represents an unusually high mutation rate in yeast, making it unlikely that $\operatorname{Lup}^{+}$is due to a point mutation. The Lup ${ }^{+}$phenotype may even be stimulated by leucine starvation because colonies continue to emerge over time. However, no effort was made to rule out continued DNA metabolism during leucine starvation (Mittler \& Lenski, 1992).

Uptake variants raise interesting questions in light of work on 'adaptive' or 'Cairnsian' mutations. Adaptive mutations arise specifically in environments that reward the cell harbouring the mutation. Moreover, these mutations only occur in genes whose products or functions are relevant to the selecting environment. Adaptive changes may occur in both bacteria (Escherichia coli) and yeast $(S$. cerevisiae), although reports continue to generate controversy (Foster, 1992; Mittler \& Lenski, 1992; Stahl, 1992). To absolutely eliminate the possibility of all growth or cell turnover in a limiting but non-lethal environment is difficult and thus exposes many claims of adaptive mutagenesis to criticism (Mittler \& Lenski, 1992). Critics charge that undetected turnover or growth could result in sufficient rounds of DNA replication to account for the accumulation of mutations in relevant genes purely by random chance. Most notably, Mittler \& Lenski (1992) have attributed the dramatic reversion frequency of a double mutant strain described by Hall (1991) to the partial growth of single revertants. Growth due to the activation of pathways like LUP1 could further confuse the issue. Even granting the possibility that the $\mathrm{Lup}^{+}$ phenotype may be a product of adaptive change, the growth of Lup ${ }^{+}$intermediates might mask the randomness of subsequent changes.

Alternatively, intermediate phenotypes might weaken the putative link between selective forces and their gene targets. Genes may not be susceptible to 'directed' changes unless growth has been completely halted, so selective pressures may be unfocused in slowly growing intermediates. Interestingly, Steele \& Jinks-Robertson (1993) found that recombination between heterologous gene duplications in yeast, wherein both alleles were defective, was stimulated during nutrient starvation. This was true during starvation for a number of different nutrients except leucine. It is interesting to speculate that perhaps Lup ${ }^{+}$cells arise at sufficient frequencies to prevent starvation-stimulated recombination.

\section{ACKNOWLEDGEMENTS}

We thank T. Brickman, N. Davis and J. Swanson for critical reading of the manuscript and $G$. Sprague, in whose laboratory Horecka performed some of this work. Work at the University of Oregon was supported by a research grant (GM 30027) from the National Institutes of Health to G. Sprague. We are grateful for the gift of strain 329-6C from H. Klein. We are indebted to S. Smaus and C. Smaus for aiding the preparation of the manuscript.

\section{REFERENCES}

Foster, P. L. (1992). Directed mutation: between unicorns and goats. J Bacteriol 174, 1711-1716.

Garrett, J. M. (1989). Characterization of $A . A T 1$ : a gene involved in the regulation of amino acid transport in Saccharomyces cerevisiae. J Gen Microbiol 135, 2429-2437. 
Grenson, M., Hou, C. \& Crabeel, M. (1970). Multiplicity of the amino acid permeases in Saccharomyces cerevisiae. IV. Evidence for a general amino acid permease. J Bacteriol 103, 770-777.

Hall, B. G. (1991). Increased tates of advantageous mutations in response to environmental challenges. ASM News 57, 82-86.

Heinemann, J. A. \& Sprague, G. F., Jr (1989). Bacterial conjugative plasmids mobilize DNA transfer between bacteria and yeast. Nature 340, 205-209.

Heinemann, J. A. \& Sprague, G. F., Jr (1991). Transmission of plasmid DNA to yeast by conjugation with bacteria. Metbods Enzymol 194, 187-195.

Hinnen, A., Hicks, J. B. \& Fink, G. R. (1978). Transformation of yeast. Proc Natl Acad Sci US A 75, 1929-1933.

Horak, J. (1986). Amino acid transport in eucaryotic microorganisms. Biochim Biophys Acta 864, 223-256.

Klein, H. L. (1988). Different types of recombinant events are controlled by the RAD1 and RAD52 genes of Saccharomyces cerevisiae. Genetics 120, 367-377.

Klein, H. L. \& Petes, T. D. (1981). Intrachromosomal gene conversion in yeast. Nature 289, 144-148.

Kotliar, N., Stella, C. A. \& Ramos, E. H. (1990). Effect of ammonium ions on L-leucine entrance in Saccbaromyces cerevisiae. Repression and inhibition of the transport systems. Rev Argent Microbiol 22, 7-16.

Mittler, J. E. \& Lenski, R. E. (1992). Experimental evidence for an alternative to directed mutation in the $b g l$ operon. Nature 356, $446-448$.
Novick, A. \& Weiner, M. (1957). Enzyme induction as an all-ornone phenomenon. Proc Natl Acad Sci US A 43, 553-566.

Pillus, L. \& Rine, J. (1989). Epigenetic inheritance of transcriptional states in S. cerevisiae. Cell 59, 637-647.

Ramos, E. H., De Bongioanni, L. C. \& Stoppani, A. O. M. (1980). Kinetics of $\mathrm{L}-\left[{ }^{14} \mathrm{C}\right]$ leucine transport in Saccharomyces cerevisiae. Effect of energy coupling inhibitors. Biochim Biophys Acta 599, 214-231.

Sherman, F. (1991). Getting started with yeast. Methods Envymol 194, 3-21.

Sherman, F. \& Wakem, P. (1991). Mapping yeast genes. Methods Enzymol 194, 38-57.

Stahl, F. W. (1992). Unicorns revisited. Genetics 132, 865-867.

Steele, D. F. \& Jinks-Robertson, S. (1993). Time-dependent mitotic recombination in Saccharomyces cerevisiae. Curr Genet 23, 423-429.

Tullin, S., Gjermansen, C. \& Kielland-Brandt, M. C. (1991). A highaffinity uptake system for branched-chain amino acids in Saccbaromyces cerevisiae. Yeast 7, 933-941.

Wainer, S. R., Boveris, A. \& Ramos, E. H. (1988). Control of leucine transport in yeast by periplasmic binding proteins. Arch Biochem Biophys 262, 481-490.

Woodward, J. R. \& Cirillo, V. P. (1977). Amino acid transport and metabolism in nitrogen-starved cells of Saccharomyces cerevisiae. J Bacteriol 130, 714-723.

Received 26 April 1993; revised 29 July 1993; accepted 10 September 1993. 